\title{
METABOLISMO OXIDATIVO E ALTERAÇÕES HEMATOBIOQUÍMICAS EM EQUINOS COM LEPTOSPIROSE SUBCLÍNICA
}

(Oxidative metabolism and hematobiochemical changes in horses with subclinical leptospirosis)

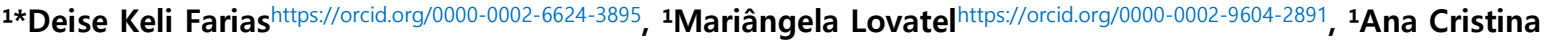

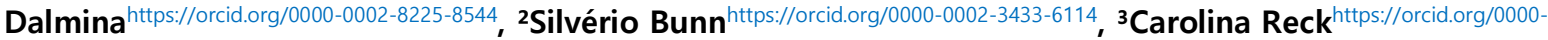

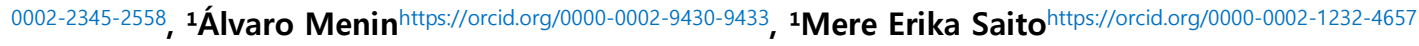

${ }^{1}$ Universidade do Estado de Santa Catarina - UDESC, Lages, SC, Brasil; ${ }^{2}$ Médico Veterinário Autônomo - Lages, SC, Brasil; Vertá - Laboratório Veterinário - Curitibanos, SC, Brasil.
}

*Corresponding author: deisekfarias@hotmail.com

RESUMO - A leptospirose é uma doença infectocontagiosa de caráter zoonótico, que afeta animais domésticos e silvestres, com grande importância para a saúde pública mundial. Nos animais, especialmente equinos, a doença se apresenta frequentemente de forma assintomática, entretanto, são considerados uma fonte de infecção para humanos e outras espécies. O presente estudo objetivou avaliar padrões do metabolismo oxidativo eritrocitário (glutationa e malondialdeído), fragilidade osmótica eritrocitária e hematobioquímicos em equinos com leptospirose subclínica para auxiliar no diagnóstico e prognóstico da infecção. Para tal foram avaliados 207 equinos, positivos ( $n=94)$ e negativos $(n=113)$ para leptospirose. Os equinos com leptospirose apresentaram mais frequentemente anticorpos anti-leptospira dos sorogrupos L. Bratislava 37,23\% (35/94), L. Icterohaemorrhagiae 23,4\% (22/94) e L. Grippotyphosa 11,7\% (11/94). As principais alterações observadas foram nos valores de hemoglobina, VGM, eosinófilos, glutationa reduzida eritrocitária, albumina e glicose $(P<0,05)$. Estas alterações evidenciam que a leptospirose em equinos pode ser uma doença silenciosa, de difícil diagnóstico e prognóstico, pois os equinos sororreagentes para Leptospira spp. apresentam mínimas alterações nos parâmetros observados, insuficientes para estabelecer um padrão de alterações entre animais positivos e corroborar com o diagnóstico. Entretanto, as medidas de diagnóstico e vigilância devem ser ativas, pois os animais podem representar um reservatório para o agente e uma fonte potencial de infecção para seres humanos.

Palavras-chave: Equinos assintomáticos; fragilidade osmótica; Leptospira spp.

ABSTRACT - Leptospirosis is a zoonotic infectious disease that affects domestic and wild animals and is of great importance for public health worldwide. In animals, especially horses, the disease often presents asymptomatic, however, they are considered a source 
of infection for humans and other species. The present study aimed to evaluate patterns of erythrocyte oxidative metabolism (glutathione and malondialdehyde), erythrocyte osmotic fragility and hematobio-chemicals in horses with subclinical leptospirosis to aid in the diagnostic and prognostic of the infection. For this purpose 207 horses were evaluated, positive $(n=94)$ and negative $(n=113)$ for leptospirosis. Horses with leptospirosis frequently showed anti-leptospira antibodies from L. Bratislava $37.23 \%$ (35/94), L. Icterohaemorrhagiae 23.4\% (22/94) and L. Grippotyphosa 11.7\% (11/94). As principais alterações observadas foram nos valores de hemoglobina, VGM, eosinófilos, glutationa reduzida eritrocitária, albumina e glicose $(P<0,05)$. These changes show that leptospirosis in horses can be a silent disease, difficult to diagnostic and prognostic. The equine serum reagents for Leptospira spp. present minimal changes in the observed parameters, insufficient to establish a pattern of changes among positive animals and corroborate with the diagnosis. However, diagnostic and surveillance measures must be active, as animals can represent a reservoir for the agent and a potential source of infection for humans.

Keywords - Osmotic fragility; Leptospira spp.; asymptomatic horses.

\section{INTRODUÇÃO}

A leptospirose é uma doença zoonótica com distribuição mundial causada por espiroquetas pertencentes ao gênero Leptospira (Ellis, 2015). Nos equinos a infecção por Leptospira spp. pode ser assintomática ou estar associada a importantes perdas reprodutivas como abortos e natimortos. Tanto leptospirose clínica quanto subclínica afetam o desempenho esportivo de equinos de alta performance (Hamond et al., 2012). Além disso, equinos infectados representam um importante reservatório do agente e uma possível fonte de infecção para outras espécies animais e um risco para a saúde pública (Faisal et al., 2012).

O padrão clínico da leptospirose e as lesões teciduais podem estar associadas ao sorovar e a capacidade de estabelecer uma resposta imunocompetente (De Brito et al., 2018). Em equinos, durante a infecção as leptospiras apresentam tropismo primariamente pelo tecido renal, olhos e trato reprodutivo da fêmea (Adler, 2014; Faisal et al., 2012), entretanto, alterações do metabolismo oxidativo e na fragilidade eritrocitária são pouco estudadas.

O metabolismo oxidativo é um fenômeno químico que envolve um desequilíbrio nos mecanismos fisiológicos do animal com grande importância para o desenvolvimento e forma de apresentação da doença (Lykkesfeldt e Svendsen, 2007). Espécies reativas do 
oxigênio (ERO) causam peroxidação lipídica da membrana celular e interferem no funcionamento das organelas alterando o metabolismo celular, sendo utilizados como importantes marcadores de dano celular (Martelli e Nunes, 2014).

Dentre os marcadores de ERO, o Malondialdeído (MDA) é um dialdeído formado como produto secundário durante a oxidação de ácidos graxos poli-insaturados, principalmente o ácido araquidônico. Há ainda, um sistema de defesa enzimático para proteger o organismo dos efeitos danosos dos radicais livres (Benzie, 1996), uma dessas enzimas é a glutationa reduzida (GSH). A GSH está presente na maioria das células, sendo considerada um dos agentes mais importantes do sistema de defesa antioxidante da célula (Ferreira e Matsubara, 1997).

A fragilidade osmótica eritrocitária (FOE) verifica a resistência osmótica dos eritrócitos em concentrações decrescentes de solução salina. A resistência depende da forma, volume, tamanho, conteúdo de hemoglobina e meia vida dos eritrócitos, e pode ser alterada por vários fatores fisiológicos ou patológicos (Elias et al., 2004). Nesse sentido, poderíamos ter uma melhor compreensão de como equinos com leptospirose subclínica tem queda de performance (Hamond et al 2012), pois a utilização deste teste permite observar variações dos resultados em enfermidades, como em alguns casos de anemia, alterações metabólicas ou carenciais e na avaliação da ação de alguns fármacos sobre o sistema hematopoiético (Sant'ana et al., 2001).

A leptospirose subclínica em equinos é uma doença silenciosa, de difícil diagnóstico, mas com possíveis implicações para a saúde animal e grande importância para a saúde pública. Entretanto as consequências da relação patógeno/hospedeiro, durante a infecção subclínica são pouco estudadas. Sendo assim, no presente estudo avaliamos padrões do metabolismo oxidativo eritrocitário (glutationa e malondialdeído), fragilidade osmótica eritrocitária e hematobioquímicos em equinos com leptospirose subclínica.

\section{MATERIAL E MÉTODOS}

Foram utilizados 207 equinos, oriundos de 26 propriedades localizadas na região Serrana Catarinense. Os equinos estudados eram todos hígidos, sem presença de sinais clínicos evidentes e sem histórico de doença clínica recente. Todos os animais eram adultos com idade média de 6,7 \pm 2,5 anos, sendo 100 machos e 107 fêmeas, não vacinados contra leptospirose. Os rebanhos utilizados foram oriundos de proprietários colaborativos, sendo colhidas amostras de no máximo 10 indivíduos de cada propriedade. As colheitas foram realizadas no período de novembro de 2017 a março de 
2018. As amostras de sangue foram colhidas por venopunção jugular, e acondicionadas em tubos a vácuo sem anticoagulante e com anticoagulante EDTA e em tubos com heparina, mantidas sob refrigeração a $10^{\circ} \mathrm{C}$. As amostras foram colhidas e em seguida processadas. O soro oriundo das amostras, foi separado em alíquotas devidamente identificadas e armazenadas a $-20^{\circ} \mathrm{C}$ para posterior análise.

As amostras de soro foram submetidas ao ensaio de Soroaglutinação Microscópica (MAT), conforme recomendação da Organização Internacional de Epizootias (OIE, 2015). Um painel de antígenos com 14 sorogrupos (18 sorovares de referência) foi gentilmente cedido pelo Laboratório de Microbiologia Veterinária da Universidade Federal Fluminense (UFF/RJ). Resumidamente, as suspensões antigênicas de leptospiras vivas dos respectivos sorovares foram adicionadas a soro diluído em série e incubadas. A aglutinação foi examinada usando microscopia de campo escuro $(100 \times)$. Os títulos foram estimados como a maior diluição sérica que aglutinou pelo menos $50 \%$ das leptospiras. Animais com título $\geq 100$ foram considerados sororreagentes. Os testes foram realizados no Laboratório de Controle de Doenças dos Animais da Universidade Federal de Santa Catarina - UFSC, Campus de Curitibanos/SC.

Para a realização do hemograma foram confeccionadas as extensões sanguíneas, coradas com corante hematológico rápido. A determinação do volume globular foi realizada pela técnica do microhematócrito (Jain, 1993). A contagem total de eritrócitos e leucócitos e a dosagem de hemoglobina foram realizadas em contador automático (SDH3 Vet, Labtest Diagnóstica, Lagoa Santa, Brasil). O volume globular médio (VGM) e a concentração de hemoglobina globular média (CHGM) foram obtidos por cálculos. A contagem diferencial de leucócitos e estimativa de plaquetas foi realizada nas extensões sanguíneas em microscopia óptica de luz (1000 x).

A determinação da concentração da proteína plasmática total (PPT) foi realizada por refratometria (Digit, Biosystems, Curitiba, Brasil) e o fibrinogênio pela técnica de precipitação pelo calor (Schalm et al., 1970).

A fragilidade osmótica eritrocitária foi determinada em concentrações crescentes de cloreto de sódio $(\mathrm{NaCl})$, pH 7,4, determinando-se a porcentagem de hemólise em cada concentração (Parpart et al., 1947). O resultado deste teste expressa a concentração de $\mathrm{NaCl}$ correspondente a $50 \%$ de hemólise $(\mathrm{H} 50)$, calculado a partir da curva dos percentuais de hemólise nas concentrações, ajustado por um modelo linear generalizado para as proporções com função de ligação Probit (Mcculloch e Searle, 2001).

Para a avaliação do metabolismo oxidativo eritrocitário foram utilizados dois ensaios. A concentração de malondialdeído (MDA) eritrocitário foi avaliada indiretamente 
pela mensuração das substâncias reativas ao ácido tiobarbitúrico (TBA), na sua concentração basal (MDA-Erit-basal) e após estímulo oxidativo (MDA-Erit estimulado) (Machado et al., 2007). Para mensuração da glutationa reduzida eritrocitária (GSH) foi realizada técnica segundo o método de Beutler (1984).

As dosagens bioquímicas foram realizadas com a utilização de kits comerciais específicos para cada análise (Labtest, Diagnóstica, Lagoa Santa, Brasil) em analisador automático (Labmax Plenno, Labtest Diagnóstica, Lagoa Santa, Brasil). Os testes bioquímicos realizados foram: ureia (Enzimátivo UV), creatinina (1010. Colorimétrico Picrato alcalino - Jaffé), aspartato aminotransferase (AST) (Cinético - UV-IFCC), fosfatase alcalina (FA) (Colorimétrico - Browers e Mc Comb modificado), proteína sérica total (PST) (Colorimétrico - Biureto), albumina (Colorimétrico - Verde de Bromocresol), globulinas (subtração do valor de albumina ao da PST), glicose (COD-Trinder), gama glutamiltransferase (GGT) (Szasz modificado), bilirrubina total (Colorimétrico - Labtest DCA), bilirrubina direta (Colorimétrico - Labtest DCA), bilirrubina indireta (subtração do valor de bilirrubina indireta ao da bilirrubina total).

As análises estatísticas foram realizadas utilizando o pacote estatístico SAS (versão 9.3, SAS Institute Inc., Cary, NC). Os dados obtidos foram submetidos ao método de análise de variância (ANOVA) e posteriormente ao teste de Tukey. As diferenças foram consideradas estatisticamente significativas quando $\mathrm{P}<0,05$.

\section{RESULTADOS}

No presente estudo foi constatada uma alta prevalência para a Lepstospira spp. $(45,4 \%)$ e os animais testados estavam aparentemente saudáveis, sem doença clínica prévia. Os sorovares de maior incidência foram L. Bratislava 37,23\% (35/94), L. Icterohaemorrhagiae 23,4\% (22/94) e L. Grippotyphosa 11,7\% (11/94). Houve sororreatividade também para os sorovares Autumnalis, Castellonis, Pomona, Hardjobovis, Guaricura, Tarassovi, Canicola e Copenhageni. Dos animais positivos 7,44\% foram reativos para mais de um sorovar. Estes dados revelaram que a Lepstospira spp. é altamente prevalente na região analisada e de difícil diagnóstico por se apresentar de forma subclínica. Neste contexto, o diagnóstico da leptospirose nos animais deve ser baseado na detecção de anticorpos (sorologia) e detecção do agente como reação em cadeia da polimerase (PCR) (OIE, 2015).

Poucos são os trabalhos que relatam sobre valores hematológicos e bioquímicos em equinos infectados naturalmente por Leptospira spp., o que poderia ser útil para melhor compreensão dos efeitos sistêmicos da infecção. É necessário salientar que as 
formas subclínicas são muito comuns (Houwers et al., 2011) como podemos observar nos dados apresentados (45,4\% de animais testados soropositivos) e os animais podem se tornar portadores inaparentes e a eliminação de leptospiras, principalmente na urina, serve como fonte de infecção para outros animais e humanos (Faisal et al., 2012).

$\mathrm{Na}$ avaliação do eritrograma foram observadas diferenças nos valores de VGM $(P<0,05)$ entre animais positivos e negativos e os valores de hemoglobina quando realizamos um comparativo entre sorovares. Verificou-se maiores concentrações de hemoglobina para o sorovar L. Grippotyphosa $(P<0,05)$. Essas diferenças observadas não apresentam relevância clínica, já que os valores se mantiveram dentro do intervalo de referência para a espécie. Os outros valores hematológicos não tiveram diferença significativa quando comparados com os valores de animais soronegativos e quando avaliados os sorovares mais frequentes separadamente e, além disso, estavam dentro dos limites dos valores de referência utilizados (Tabela 1).

Quanto ao leucograma, houve diferença estatística nos valores de eosinófilos $(P<0,05)$ entre animais positivos e negativos para leptospirose. Entretanto, os valores se mantiveram dentro dos intervalos de referência para a espécie (Jain, 1993), não possuindo relevância clínica. Pinna et al. (2010) encontraram discreto aumento no número de linfócitos em equinos soropositivos e com histórico de falhas reprodutivas. Não ocorreram alterações significativas neste estudo, provavelmente, pelo fato de os animais não apresentarem sinais clínicos.

Para os valores de proteína plasmática total (PPT) e de fibrinogênio não houve diferença estatística significativa entre os grupos estudados. Pode-se observar valores acima do intervalo de referência para os animais reativos ao sorovar L. Grippotyphosa. Aumento das concentrações plasmáticas de fibrinogênio pode indicar processos inflamatórios agudos (Thrall et al., 2015). Nos animais estudados não foram verificadas outras alterações que indicassem algum processo inflamatório agudo. 
Tabela 1 - Valores médios \pm desvio padrão do eritrograma, leucograma, proteína plasmática total e fibrinogênio conforme sorologia positiva e negativa para Leptospira spp. e separadamente pelos sorovares de maior prevalência.

\begin{tabular}{|c|c|c|c|c|c|c|}
\hline Eritrograma & $\begin{array}{c}\text { Negativos } \\
(n=113)\end{array}$ & $\begin{array}{c}\text { Positivos } \\
\text { (n=94) }\end{array}$ & $\begin{array}{c}\text { Bratislava } \\
(\mathrm{n}=35)\end{array}$ & $\begin{array}{c}\text { Icterohae } \\
\text { morrhagiae } \\
(\mathrm{n}=22)\end{array}$ & $\begin{array}{c}\text { Grippotyphosa } \\
\qquad(\mathrm{n}=11)\end{array}$ & $\begin{array}{l}\text { Valores de } \\
\text { referência * }\end{array}$ \\
\hline $\begin{array}{l}\text { Eritrócitos } \\
\left(\times 10^{6} / \mu \mathrm{L}\right)\end{array}$ & $8,68 \pm 1,2$ & $8,59 \pm 1,1$ & $8,65 \pm 1,1$ & $8,51 \pm 0,9$ & $8,5 \pm 0,9$ & $6,5-12,5$ \\
\hline $\begin{array}{l}\text { Hemoglobina } \\
(\mathrm{g} / \mathrm{dL})\end{array}$ & $11,68 \pm 1,6^{\mathrm{B}}$ & $11,87 \pm 1,6$ & $11,79 \pm 1,5^{\mathrm{B}}$ & $11,31 \pm 1,5^{\mathrm{B}}$ & $13,16 \pm 2,1^{\mathrm{A}}$ & $11-19$ \\
\hline VG (\%) & $35,05 \pm 4,6$ & $35,89 \pm 4,7$ & $36,4 \pm 5,1$ & $34,85 \pm 3,2$ & $37,88 \pm 5,2$ & $32-52$ \\
\hline VGM (fL) & $40,58 \pm 3,4^{a}$ & $41,89 \pm 3,4^{b}$ & $42,1 \pm 2,4$ & $41,26 \pm 3,2$ & $44,62 \pm 4,6$ & $34-58$ \\
\hline CHGM (\%) & $33,34 \pm 1,5$ & $33,07 \pm 1,6$ & $32,52 \pm 1,5$ & $32,97 \pm 1,5$ & $33,89 \pm 2,1$ & $31-37$ \\
\hline $\begin{array}{l}\text { Plaquetas } \\
\left(\times 10^{3} / \mu \mathrm{L}\right)\end{array}$ & $184,1 \pm 70,7$ & $190,2 \pm 55,8$ & $197 \pm 41,1$ & $189,9 \pm 65,7$ & $180,7 \pm 59,3$ & $100-350$ \\
\hline $\begin{array}{l}\text { Leucócitos } \\
\text { totais }(/ \mu \mathrm{L})\end{array}$ & $8979 \pm 2282$ & $9295 \pm 2205$ & $10016 \pm 2370$ & $9117 \pm 1659$ & $9730 \pm 1637$ & $5500-12500$ \\
\hline $\begin{array}{c}\text { Segmentados } \\
(/ \mu \mathrm{L})\end{array}$ & $4804 \pm 1501$ & $5070 \pm 1490$ & $5550 \pm 1633$ & $4961 \pm 1270$ & $5682 \pm 1209$ & $2700-6700$ \\
\hline Linfócitos $(/ \mu \mathrm{L})$ & $3670 \pm 1630$ & $3608 \pm 1336$ & $3769 \pm 1348$ & $3306 \pm 1218$ & $3592 \pm 996$ & $1500-5500$ \\
\hline Eosinófilos $(/ \mu \mathrm{L})$ & $315 \pm 302^{a}$ & $412 \pm 386^{b}$ & $441 \pm 379$ & $524 \pm 517$ & $313 \pm 146$ & $0-950$ \\
\hline Basófilos $(/ \mu \mathrm{L})$ & $46 \pm 85$ & $72 \pm 127$ & $94 \pm 167$ & $105 \pm 138$ & $55 \pm 66$ & $0-170$ \\
\hline Monócitos $(/ \mu \mathrm{L})$ & $141 \pm 154$ & $128 \pm 127$ & $156 \pm 182$ & $121 \pm 82$ & $107 \pm 73$ & $0-800$ \\
\hline PPT (g/dL) & $6,78 \pm 0,68$ & $6,87 \pm 0,65$ & $6,98 \pm 0,54$ & $6,88 \pm 0,87$ & $6,07 \pm 0,45$ & $5,3-8,3$ \\
\hline $\begin{array}{l}\text { Fibrinogênio } \\
\text { (mg/dL) }\end{array}$ & $340,7 \pm 62,2$ & $313,8 \pm 154,7$ & $293,7 \pm 154,3$ & $350 \pm 146$ & $466,6 \pm 163,2$ & $100-400$ \\
\hline
\end{tabular}

Letras iguais representam médias iguais, letras diferentes indicam diferença estatística, $\mathrm{P}<0,05$.

${ }^{a b}$ entre animais positivos e negativos $e^{A B}$ entre sorovares e animais negativos.

*Jain (1993); Kaneko (2008).

Verificou-se diferença estatística nas concentrações de GSH entre animais positivos e negativos para Lepstospira spp. $(P=0,05)$, já entre os valores de MDA não houve diferença significativa (Tabela 2). Embora não tenha ocorrido diferença significativa nas concentrações do MDA, pôde-se observar um discreto aumento nos valores dos animais positivos. Esses achados podem sugerir a produção de espécies reativas do oxigênio e de peroxidação lipídica. A GSH é um dos principais antioxidantes que age de forma preventiva, evitando que as ERO causem danos às células. Uma de suas funções é neutralizar os produtos gerados durante o processo de peroxidação lipídica. Na presença de ERO, a GSH é oxidada por ação da glutationa peroxidase, diminuindo os níveis circulantes de GSH (Hanschmann et al., 2013). 
Tabela 2 - Valores médios \pm desvio padrão de glutationa reduzida eritrocitária (GSH), malondialdeído (MDA) e fragilidade osmótica eritrocitária (FOE) expresso como correspondentes à concentração de $\mathrm{NaCl}$ com $50 \%$ de hemólise (H50) conforme sorologia positiva e negativa para Leptospira spp. e separadamente pelos sorovares de maior prevalência.

\begin{tabular}{cccccc}
\hline & $\begin{array}{c}\text { Negativos } \\
(\mathbf{n}=\mathbf{1 1 3})\end{array}$ & $\begin{array}{c}\text { Positivos } \\
(\mathbf{n}=\mathbf{9 4})\end{array}$ & $\begin{array}{c}\text { Bratislava } \\
(\mathbf{n}=\mathbf{3 5})\end{array}$ & $\begin{array}{c}\text { Icterohae } \\
\text { morrhagiae } \\
(\mathbf{n}=\mathbf{2 2})\end{array}$ & $\begin{array}{c}\text { Grippotyphosa } \\
(\mathbf{n}=\mathbf{1 1})\end{array}$ \\
\hline $\begin{array}{c}\mathbf{G S H} \\
(\boldsymbol{\mu} \mathbf{m o l} / \mathbf{g ~ H b}) \\
\mathbf{M D A}\end{array}$ & $5,16 \pm 1,89^{\mathrm{a}}$ & $4,54 \pm 2,68^{\mathrm{b}}$ & $3,39 \pm 2,6$ & $4,73 \pm 2,89$ & $4,96 \pm 2,65$ \\
$\begin{array}{c}(\mathbf{n M} / \mathbf{g ~ H b}) \\
\mathbf{F O E} \\
(\mathbf{H 5 0})\end{array}$ & $0,625 \pm 0,703$ & $0,738 \pm 0,518$ & $0,748 \pm 0,527$ & $0,912 \pm 0,564$ & $0,675 \pm 0,43$ \\
\hline
\end{tabular}

Letras iguais representam médias iguais, letras diferentes indicam diferença estatística, $\mathrm{P}=0,05$

Pesquisadores verificaram aumento de MDA em bovinos com leptospirose clínica, assim como redução de GSH (Erdogan et al., 2008). Deger et al. (2009) demonstraram um aumento da peroxidação lipídica e uma redução da atividade da GSH em equinos naturalmente infectados por Theileria equi. Como o presente estudo não utilizou animais com doença clínica, as alterações encontradas são discretas, mas evidenciam que mesmo assim, podem ocorrer alterações discretas no metabolimo oxidativo.

Os dados avaliados no presente estudo não apresentaram diferença estatística para fragilidade eritrocitária. Apesar de não apresentar diferença estatística, há uma tendência de ocorrer maior fragilidade eritrocitária quando observados os valores para os animais reativos ao sorovar L. Icterohaemorrhagiae, no qual foram verificados valores maiores de MDA eritrocitário, provavelmente devido aos efeitos deletérios das espécies reativas do oxigênio com consequente lipoperoxidação e constatada pela maior $\mathrm{FOE}$, que contribui com dados em relação ao metabolismo oxidativo na leptospirose subclínica.

Quanto à avaliação da bioquímica clínica, somente os valores de albumina e glicose foram estatisticamente diferentes $(P<0,01)$ entre equinos negativos e positivos para Leptospira spp. (Tabela 3). A diminuição da albumina em animais soropositivos para Leptospira spp. também pode indicar estresse oxidativo neste estudo. A albumina é uma proteína de fase aguda negativa, entre suas muitas funções biológicas, possui uma atividade antioxidante significativa (Bourdon e Blache, 2001; Kaneko et al., 2008). Assim como foi constatada diminuição nas concentrações de $\mathrm{GSH}$, a albumina também pode estar sendo mobilizada para combater radicais livres circulantes. No presente estudo os animais negativos apresentaram concentração de albumina menor que os valores de referência utilizados, já as concentrações de globulinas foram maiores. Valores semelhantes já foram descritos em equinos saudáveis (Cancelier, 2017; Todeschini, 2017). 
Em equinos, a diminuição dos valores de albumina isoladamente não tem correlação com perda de função hepática e se estima que cerca de $20 \%$ dos animais saudáveis manifestam hipoalbuminemia (Thrall et al., 2015), corroborando com o que foi relatado.

A atividade de GGT permaneceu sem diferença estatística entre os grupos, mas os valores encontrados estão discretamente acima do intervalo de referência para a espécie (Kaneko et al., 2008). Estes valores, associados aos demais achados, não evidenciam anormalidades. A GGT é uma enzima que pode estar elevada em lesão hepática aguda, em que sua atividade pode estar com valores de 5 a 30 vezes acima do normal (Thrall et al., 2015) e no presente estudo não chegou a duas vezes o valor superior de referência.

A concentração de glicose foi estatisticamente maior nos animais negativos para Leptospira spp. $(\mathrm{P}<0,01)$. Como os valores se mantiveram dentro dos valores de referência para espécie (Kaneko et al., 2008), provavelmente essa diferença seja oriunda de um achado ocasional.

Pesquisadores observaram que equinos com sororreatividade para o sorovar $\mathrm{L}$. Bratislava, mesmo na presença de problemas reprodutivos, não apresentaram alteração consistentes ou importantes para os valores de hematologia e bioquímica sérica (Pinna et al., 2010), assim como os resultados encontrados neste estudo. 
Tabela 3 - Valores médios \pm desvio padrão de bioquímica clínica conforme sorologia positiva e negativa para Leptospira spp. e separadamente por cada sorovar que foram reagentes.

\begin{tabular}{|c|c|c|c|c|c|c|}
\hline & $\begin{array}{c}\text { Negativos } \\
(n=113)\end{array}$ & $\begin{array}{c}\text { Positivos } \\
\text { (n=94) }\end{array}$ & $\begin{array}{c}\text { Bratislava } \\
\quad(n=35)\end{array}$ & $\begin{array}{l}\text { Icterohae- } \\
\text { morrhagiae } \\
(\mathrm{n}=22)\end{array}$ & $\begin{array}{c}\text { Grippoty- } \\
\text { phosa } \\
(n=11)\end{array}$ & $\begin{array}{l}\text { Valores de } \\
\text { referência * }\end{array}$ \\
\hline $\begin{array}{l}\text { Ureia } \\
\text { (mg/dL) }\end{array}$ & $35,00 \pm 8,69$ & $34,66 \pm 9,12$ & $36,53 \pm 9,94$ & $33,35 \pm 8,65$ & $34,11 \pm 10,49$ & $21,4-51,4$ \\
\hline $\begin{array}{c}\text { Creatinina } \\
\text { (mg/dL) }\end{array}$ & $1,48 \pm 0,35$ & $1,48 \pm 0,46$ & $1,57 \pm 0,62$ & $1,40 \pm 0,39$ & $1,31 \pm 0,41$ & $1,20-1,90$ \\
\hline $\begin{array}{l}\text { Proteína sérica } \\
\text { total }(\mathrm{g} / \mathrm{dL})\end{array}$ & $6,76 \pm 0,7$ & $6,84 \pm 0,77$ & $6,94 \pm 0,7$ & $6,9 \pm 0,91$ & $6,64 \pm 0,48$ & $5,20-7,90$ \\
\hline $\begin{array}{l}\text { Albumina } \\
\text { (g/dL) }\end{array}$ & $2,45 \pm 0,29 a$ & $2,35 \pm 0,26^{b}$ & $2,37 \pm 0,16$ & $2,18 \pm 0,28$ & $2,38 \pm 0,24$ & $2,60-3,90$ \\
\hline $\begin{array}{l}\text { Globulinas } \\
\text { (g/dL) }\end{array}$ & $4,30 \pm 0,75$ & $4,49 \pm 0,8$ & $4,56 \pm 0,71$ & $4,71 \pm 0,94$ & $4,30 \pm 0,64$ & $2,60-4,00$ \\
\hline $\begin{array}{c}\text { Fosfatase } \\
\text { alcalina (U/L) }\end{array}$ & $222,5 \pm 75,44$ & $226,4 \pm 87,87$ & $232,96 \pm 94,32$ & $248,57 \pm 96,28$ & $190 \pm 61,63$ & $143-395$ \\
\hline $\begin{array}{l}\text { AST } \\
(U / L)\end{array}$ & $297,5 \pm 129,3$ & $278,8 \pm 117,7$ & $276,34 \pm 78,57$ & $258,48 \pm 79,51$ & $287,66 \pm 76,65$ & $226-366$ \\
\hline $\begin{array}{l}\text { GGT } \\
(U / L)\end{array}$ & $18,61 \pm 8,78$ & $18,84 \pm 13,0$ & $18,12 \pm 5,04$ & $19,9 \pm 20,6$ & $23 \pm 17,43$ & $4,30-13,40$ \\
\hline $\begin{array}{c}\text { Bilirrubina } \\
\text { Total (mg/dL) }\end{array}$ & $1,34 \pm 0,84$ & $1,22 \pm 0,86$ & $0,96 \pm 0,77$ & $1,02 \pm 0,66$ & $1,33 \pm 1,19$ & $1,00-2,00$ \\
\hline $\begin{array}{c}\text { Bilirrubina } \\
\text { Direta }(\mathrm{mg} / \mathrm{dL})\end{array}$ & $0,31 \pm 0,07$ & $0,31 \pm 0,08$ & $0,3 \pm 0,09$ & $0,33 \pm 0,09$ & $0,24 \pm 0,1$ & $0,00-0,40$ \\
\hline Bilirrubina & & & & & & \\
\hline $\begin{array}{l}\text { Indireta } \\
\text { (mg/dL) }\end{array}$ & $1,03 \pm 0,85$ & $0,91 \pm 0,86$ & $0,65 \pm 0,75$ & $0,68 \pm 0,64$ & $1,09 \pm 1,15$ & $0,20-2,00$ \\
\hline $\begin{array}{l}\text { Glicose } \\
\text { (mg/dL) }\end{array}$ & $91,2 \pm 16,9$ aA & $79,9 \pm 17,8^{b}$ & $75,0 \pm 14,7^{\mathrm{B}}$ & $75,9 \pm 15,7^{B}$ & $75,66 \pm 15,6^{B}$ & $75-115$ \\
\hline
\end{tabular}

\section{CONCLUSÃO}

Os equinos soropositivos para Leptospira spp. e assintomáticos não apresentaram nenhuma alteração consistente nos valores hematológicos, de bioquímica sérica ou do metabolismo oxidativo, demostrando que estes exames não são suficientes para a identificação de infecção por este patógeno em animais sem doença clínica evidente. Sendo assim, com exames considerados rotineiros não é possível a confirmação ou mesmo a suspeita de tal infecção. A detecção de anticorpos é mais eficiente para indicar o contágio. Mais estudos devem ser conduzidos para comprovar se esta é uma condição estável dos indivíduos, ou se em determinados períodos a doença pode manifestar formas clínicas.

\section{Agradecimentos}

Este estudo teve apoio da Coordenação de Aperfeiçoamento de Pessoal de Nível Superior (CAPES) e a Fundação de Amparo à Pesquisa do Estado de Santa Catarina (Fapesc). 


\section{Notas informativas}

Este trabalho está de acordo com as normas editadas pelo Conselho Nacional de Controle da Experimentação Animal (CONCEA) e foi previamente aprovado pela Comissão de Ética no Uso de Animais pela Universidade do Estado de Santa Catarina (CEUA/UDESC), protocolado sob o CEUA n 4299250816.

\section{REFERÊNCIAS}

ADLER, B. Pathogenesis of leptospirosis: cellular and molecular aspects. Veterinary Microbiology, v. 172, n. 3-4, p. 353-8, 2014.

BENZIE, I. F. F. Lipid Peroxidation: a review of cases, consequences, measurements and dietary influences. International Journal of Food Sciences and Nutrition, v. 47, p. 233261, 1996.

BEUTLER, E. Glutathione. In: (Ed.). Red cell metabolism: a manual of biochemical methods. 3. Orlando: Grune e Stratton, 1984. p.131-134.

BOURDON, E.; BLACHE, D. The importance of proteins in defense against oxidation. Antioxidants e Redox Signaling, v. 3, n. 2, p. 293-311, 2001.

CANCELIER, C. D. L. Hematologia, bioquímica e metabolismo oxidativo em éguas gestantes da raça crioula. 2017. 64 p. (Dissertação de Mestrado). Centro de Ciências Agroveterinárias - CAV, Universidade do Estado de Santa Catarina - UDESC, Lages - SC.

DE BRITO, T.; SILVA, A. M. G.; ABREU, P. A. E. Pathology and pathogenesis of human leptospirosis: a commented review. Revista do Instituto de Medicina Tropical de São Paulo, v. 60, n. 23, p. 1-10, 2018.

DEGER, S.; DEGER, Y.; BICEK, K. et al. Status of peroxidation, antioxidants, and oxidation products of nitric oxide in equine babesiosis: status of antioxidant and oxidant in equine babesiosis. Journal of Equine Veterinary Science. v. 29, n.10, p.743-747, 2009.

ELIAS, F.; LUCAS, S.R.R.; HAGIWARA, M.K. et al. Fragilidade osmótica eritrocitária em gatos acometidos por hepatopatias e gatos com insuficiência renal. Ciência Rural, v. 34, n. 2, p. 413-418, 2004.

ELLIS, W. A. Animal leptospirosis. Current Topics Microbiology Immunology, v. 387, p. 99-137, 2015.

ERDOGAN, H. M.; KARAPEHLIVAN, M.; CITIL, M. et al. Serum sialic acid and oxidative stress parameters changes in cattle with leptospirosis. Veterinary Research Communications, v. 32, n. 4, p. 333-9, Apr 2008. 
FAISAL, S. M.; MCDONOUGH, S. P.; CHANG, Y.-F. Leptospira: invasion, pathogenesis and persistence. In: ME, E. (Ed.). The pathogenic spirochetes: strategies for evasion of host immunity and persistence. New York, NY: Springer Science, 2012. p.143-172.

FERREIRA, A. L. A.; MATSUBARA, L. S. Radicais livres: conceitos, doenças relacionadas, sistema de defesa e estresse oxidativo. Revista da Associação Medica Brasileira, v. 43, n. 1, p. 61-68, 1997.

HAMOND, C.; MARTINS, G.; LILENBAUM, W. Subclinical leptospirosis may impair athletic performance in racing horses. Tropical Animal Health Production, v. 44, n. 8, p. 1927-30, 2012.

HANSCHMANN, E.M.; GODOY, J.R.; BERNDT, C. et al. Thioredoxins, glutaredoxins, and peroxiredoxins--molecular mechanisms and health significance: from cofactors to antioxidants to redox signaling. Antioxidants \& Redox Signaling, v. 19, n. 13, p. 1539605, 2013.

HOUWERS, D.J.; GORIS, M.G.; ABDOEL, T. et al. Agglutinating antibodies against pathogenic Leptospira in healthy dogs and horses indicate common exposure and regular occurrence of subclinical infections. Veterinary Microbiology, v. 148, n. 2-4, p. 449-51, 2011.

JAIN, N. C. Essentials of Veterinary Hematology. Philadelphia: Lea \& Febiger, 1993. 417p.

KANEKO, J. J.; HARVEY, J. W.; BRUSS, M. L. Clinical biochemistry of domestic animals. New York: Academic press, 2008. 916p.

LYKKESFELDT, J.; SVENDSEN, O. Oxidants and antioxidants in disease: oxidative stress in farm animals. The Veterinary Journal, v. 173, n. 3, p. 502-11, 2007.

MACHADO, L. P.; SAITO, M.E.; SILVEIRA, V.F. et al. Susceptibilidade eritrocitária ao estresse osmótico em equinos da raça Árabe: efeito do exercício, treinamento e suplementação com vitamina E. Revista Universidade Rural Série Ciências da Vida, v. 27, p. 134-136, 2007.

MARTELLI, F.; NUNES, F.M.F. Radicais Livres: em busca do equilíbrio. Ciência e Cultura, v. 66, n. 3, p. 54-57, 2014.

CCULLOCH, C. E.; SEARLE, S. R. Linear and generalizaded linear mixed models. New York: Wiley, 2001. 358p.

OIE. Dourine. In: Manual of Diagnostic Tests and Vaccines for Terrestrial Animals 2015. 2015. ed. [s.l.] OIE, 2015. 500p.

PARPART, A. K.; LORENZ, P. B.; PARPART, E.R. et al. The osmotic resistance (fragility) of human red cells. Journal of Clinical Investigation, v. 26, n. 4, p. 636-40, 1947. 
PINNA, M.; MARTINS, G; FREIRE, I. et al. Seropositivity to Leptospira interrogans serovar Bratislava associated to reproductive problems without significant biochemical or hematological alterations in horses. Ciência Rural, v. 40, n. 10, p. 2214-2217, 2010.

SANT'ANA, V. A. C.; BIRGEL, E. H.; MOURÃO, G. B. Fragilidade osmótica dos eritrócitos de bovinos das raças Holandesa, Girolando e Gir, criados no Estado de Säo Paulo. Ciência rural, v. 31, n. 4, p. 609-614, 2001.

SCHALM, O. W.; SMITH, R; KANEKO, J. J. Plasma protein: fibrinogen ratios in dogs, cattle and horses. Part 1. Influence of age on normal values and explanation of use in disease. California Veterinarian, v. 24, p. 9-11, 1970.

THRALL, M. A.; WEISER, G.; ALLISON, B. W. et al. Hematologia e bioquímica clínica veterinária. 2.ed. Rio de Janeiro: Guanabara Koogan, 2015. 1590 p.

TODESCHINI, P. R. B. Avaliação hematológica, bioquímica e do metabolismo oxidativo em equinos da raça crioula submetidos à prova simulada de laço comprido. 2017. Lages, 36 p. Dissertação (Mestrado em Ciência Animal) - Curso de Pós- Graduação em Ciência Animal, Universidade do Estado de Santa Catarina - UDESC. 